\title{
Short term exposure to air pollution and stroke: systematic review and meta-analysis
}

\author{
Anoop S V Shah,, ${ }^{1}$ Kuan Ken Lee, ${ }^{1}$ David A McAllister, ${ }^{2}$ Amanda Hunter, ${ }^{1}$ Harish Nair, ${ }^{2}$ \\ William Whiteley, ${ }^{3}$ Jeremy P Langrish, ${ }^{1}$ David E Newby, ${ }^{1}$ Nicholas L Mills ${ }^{1}$
}

${ }^{1}$ BHF/University Centre for Cardiovascular Science, University of Edinburgh, Edinburgh EH16 4SB, UK

${ }^{2}$ Centre of Population Health Sciences, University of

Edinburgh, Edinburgh, UK

${ }^{3}$ Centre for Clinical Brain

Sciences, University of

Edinburgh, Edinburgh, UK

Correspondence to:

A S V Shahanoopsshah@gmail. com

Additional material is published online only. To view please visit the journal online (http:// dx.doi.org/10.1136/BMJ.h1295) Cite this as: BMJ 2015;350:h1295 doi:10.1136/bmj.h1295

Accepted: 05 February 2015

\section{ABSTRACT}

OBJECTIVE

To review the evidence for the short term association between air pollution and stroke.

DESIGN

Systematic review and meta-analysis of observational studies

\section{DATA SOURCES}

Medline, Embase, Global Health, Cumulative Index to Nursing and Allied Health Literature (CINAHL), and Web of Science searched to January 2014 with no language restrictions.

\section{ELIGIBILITY CRITERIA}

Studies investigating the short term associations (up to lag of seven days) between daily increases in gaseous pollutants (carbon monoxide, sulphur dioxide, nitrogen dioxide, ozone) and particulate matter $\left(<2.5 \mu \mathrm{m}\right.$ or $<10 \mu \mathrm{m}$ diameter $\left(\mathrm{PM}_{2.5}\right.$ and $\left.\left.\mathrm{PM}_{10}\right)\right)$, and admission to hospital for stroke or mortality.

MAIN OUTCOME MEASURES

Admission to hospital and mortality from stroke. RESULTS

From 2748 articles, 238 were reviewed in depth with 103 satisfying our inclusion criteria and 94 contributing to our meta-estimates. This provided a total of 6.2 million events across 28 countries. Admission to hospital for stroke or mortality from stroke was associated with an increase in concentrations of carbon monoxide (relative risk 1.015 per $1 \mathrm{ppm}, 95 \%$ confidence interval 1.004 to 1.026 ), sulphur dioxide (1.019 per $10 \mathrm{ppb}, 1.011$ to 1.027), and nitrogen dioxide (1.014 per $10 \mathrm{ppb}, 1.009$ to 1.019). Increases in $\mathrm{PM}_{2.5}$ and $\mathrm{PM}_{10}$ concentration were also associated with admission and mortality $(1.011$ per 10 $\hat{1} 1 / 4 \mathrm{~g} / \mathrm{m}^{3}$ (1.011 to 1.012$)$ and 1.003 per $10 \mu \mathrm{g} / \mathrm{m}^{3}(1.002$ to 1.004$)$, respectively). The weakest association was seen with ozone (1.001 per $10 \mathrm{ppb}, 1.000$ to 1.002).

\section{WHAT IS ALREADY KNOWN ON THIS TOPIC}

Stroke is a major cause of disability worldwide with an increasing incidence, particularly in low and middle income countries

While exposure to outdoor air pollution is strongly associated with acute cardiac events, the relation between air pollution and stroke is less clear

\section{WHAT THIS STUDY ADDS}

Our findings suggest a strong association between short term exposure to both gaseous (except ozone) and particulate air pollution, and admission to hospital for stroke and mortality from stroke

These associations were strongest in low and middle income countries, suggesting the need for policy changes to reduce personal exposure to air pollutants especially in highly polluted regions
Strongest associations were observed on the day of exposure with more persistent effects observed for $\mathrm{PM}_{2-5}$.

\section{CONCLUSION}

Gaseous and particulate air pollutants have a marked and close temporal association with admissions to hospital for stroke or mortality from stroke. Public and environmental health policies to reduce air pollution could reduce the burden of stroke.

SYSTEMATIC REVIEW REGISTRATION

PROSPERO-CRD42014009225.

\section{Introduction}

Outdoor air pollution is an important risk factor for cardiovascular disease throughout the world, with particulate air pollution alone responsible for over three million deaths each year. ${ }^{12}$ Increases in concentrations of daily air pollution are associated with acute myocardial infarction ${ }^{3}$ and admission to hospital or death from heart failure. ${ }^{4}$ These associations could be mediated through direct and indirect effects of exposure to air pollutants on vascular tone, endothelial function, thrombosis, and myocardial ischaemia. ${ }^{5-8}$

Stroke accounts for five million deaths each year and is a major cause of disability. ${ }^{9}$ The incidence of stroke is increasing, particularly in low and middle income countries, where two thirds of all strokes occur. ${ }^{10}$ The global burden of stroke related disability is therefore high and continues to rise. This has been primarily attributed to an ageing population in high income countries and the accumulation of risk factors for stroke, such as smoking, hypertension, and obesity, in low and middle income countries. ${ }^{11} 12$ The impact of environmental factors on morbidity and mortality from stroke, however, might be important and is less certain. ${ }^{13-15}$ Given similarities in the pathophysiology of acute coronary syndrome and ischaemic stroke, it is plausible that air pollution is also an important and modifiable risk factor. ${ }^{34}$

To provide global policy makers with the best estimates of the effect of short term exposure to air pollution on risk of stroke, we systematically reviewed studies examining the association between air pollution and admission to hospital for stroke or mortality from stroke.

\section{Methods}

Databases, sources, and searches

We searched Medline and Embase (from 1948 to 21 January 2014), Global Health, Cumulative Index to Nursing and Allied Health Literature (CINAHL), and Web of Science with detailed search terms for: "stroke”, "cerebrovascular 
disease”, "air pollution”, “carbon monoxide”, "sulphur dioxide", "nitrogen dioxide”, "ozone”, and "particulate matter" (see appendix 1 for detailed search strategy). We also hand searched the bibliographies of all the included studies and relevant review articles to identify any remaining studies.

\section{Selection of articles and extraction of data}

Original studies were included if they evaluated short term associations (up to a lag of seven days) between carbon monoxide, sulphur dioxide, nitrogen dioxide, ozone, and particulate matter $\mathrm{PM}_{2.5}$ (fine particles $<2.5 \mu \mathrm{m}$ in size) or $\mathrm{PM}_{10}$ (coarse particles $<10 \mu \mathrm{m}$ in size) and admission to hospital for stroke or mortality from stroke (appendix 2). Admission or mortality had to be recorded as an end point. Our search criteria imposed no language restrictions. We did not include studies that evaluated association of long term exposure to air pollution and stroke (appendix 2) or abstracts, but we did include short reports.

One investigator (ASVS) performed the initial screening of titles and abstracts. A second investigator (KKL) assessed a random sample of 200 initial titles and abstracts during the initial screening process, and no cases of disagreement were found. Two investigators (ASVS and KKL) were involved in the examination of the full text reports for eligibility of studies according to our prespecified review protocol (PROSPERO registration CRD42014009225). The inter-rater agreement for eligibility of studies was 0.95 (95\% confidence interval 0.91 to 0.99). ASVS and KKL independently extracted the required parameters of each study, and conflicts were adjudicated by a third author (AH). We contacted authors for additional data or clarification for our meta-analysis where these were not presented.

\section{Study design}

We included both case crossover and time series studies (appendix 3). The case crossover design uses conditional logistic regression to compare exposure in a case period when the event occurred with exposure in specified control periods, with adjustment for individual characteristics such as age, sex, and comorbidity as well as secular trends and seasonal patterns with a time stratified approach. It assumes that short term time varying risk factors (such as smoking) are constant within reference periods ${ }^{41617}$ and therefore do not confound rapidly fluctuating parameters such as concentrations of air pollution and other meteorological parameters.

Time series studies measure the association between exposure and outcome with regression analysis to adjust for confounding factors, such as meteorological variables, but are less effective at controlling for secular trends such as seasonality. ${ }^{18}$

\section{Data synthesis}

We pooled relative risks for a standardised increment in pollutant concentration as follows: $10 \hat{\mathrm{I}} 1 / 4 \mathrm{~g} / \mathrm{m}^{3}$ for $\mathrm{PM}_{2.5}$ and $\mathrm{PM}_{10}, 10 \mathrm{ppb}$ (parts per billion) for nitrogen dioxide $\left(\mathrm{NO}_{2}\right)$, sulphur dioxide $\left(\mathrm{SO}_{2}\right)$, and ozone $\left(\mathrm{O}_{3}\right)$, and $1 \mathrm{ppm}$ (parts per million) for carbon monoxide (CO). These increments were used in most studies and in previous meta-analysis. ${ }^{34}$ We calculated standardised risk estimates for each study using the following formula:

Five studies reported natural log of relative risk and the corresponding $t$ statistic value or standard error of mean. ${ }^{19-23}$ Studies that expressed substratified risk estimates by age, location, season, sex, and type of stroke rather than an overall risk estimate were pooled separately.

\section{Additional analysis}

We used the shortest lag presented to derive the overall estimates consistent with previous studies. ${ }^{34}$ The temporal association between air pollution and admission to hospital for stroke or mortality from stroke were further stratified according to time lags. Summary estimates for lag 0 (days) refer to the risk of an event per increment in air pollution on the day of the event. Lag 1 refers to risk estimates per increment in air pollution concentrations one day before the event. Most studies presented single lag analysis but only a few studies explicitly reported use of distributed lag models (appendix 4). We were therefore unable to further stratify studies reporting single lag analysis using distributed lag models. Several studies reported data based on pollutant concentrations over cumulative lags (for example lag $0-1$ or lag $0-2$ ) and were not suitable for pooling in single lag analysis.

We performed additional prespecified analysis stratified by study design, age, sex, outcome, and type of stroke. For nitrogen dioxide and $\mathrm{PM}_{10}$ we further provided pooled estimates stratified by the nation's income status as defined by the World Bank using the gross national income per capita. ${ }^{24}$ We provided pooled estimates for stratified variables where at least three or more estimates were available.

\section{Risk of bias}

We assessed each individual study for risk of bias across three parameters: selection bias, assessment of exposure, and adjustment for confounders. We then carried out sensitivity analysis eliminating those studies with high risk of bias.

\section{Selection bias}

We did not have access to primary data and therefore were reliant on the case definitions used by the authors of the individual studies. Most studies (83\%, 86/103 studies), however, used ICD-9 (international classification of diseases, ninth revision) codes 430438 and ICD-10 (international classification of diseases, 10th revision) codes I60-I69 (appendix 4). Studies that used all clinical information, including brain imaging, to define stroke or those that used an inclusive definition of stroke (ICD-9 codes 430-437 and ICD-10 codes I60-I68) were considered to be at low risk of selection bias. Studies that used a less inclusive definition were considered to be at increased risk of selection bias. 


\section{Exposure assessment}

Accuracy of the measurement of exposure was difficult to assess because of variable reporting in the primary studies. The frequency of measurement (daily or intermittent monitoring), however, was reported to a high standard, and we considered studies that used daily measurement to be at low risk of bias.

\section{Adjustment of confounders}

Adjustment for meteorological parameters, time trends, seasonality, and influenza outbreaks are summarised in the data supplement (appendix 4). Studies that adjusted for at least three confounders were considered to be at low risk of bias.

\section{Statistical analysis}

Based on our previous analysis, ${ }^{4}$ we anticipated a larger degree of variation and heterogeneity in the overall effect estimates between studies because of different study designs, methods of analysis, different exposure lags, and geographical and population differences. As we did not assume that the "true effect" estimate would be the same across all studies, we used a prespecified random effects model (maximum likelihood approach)

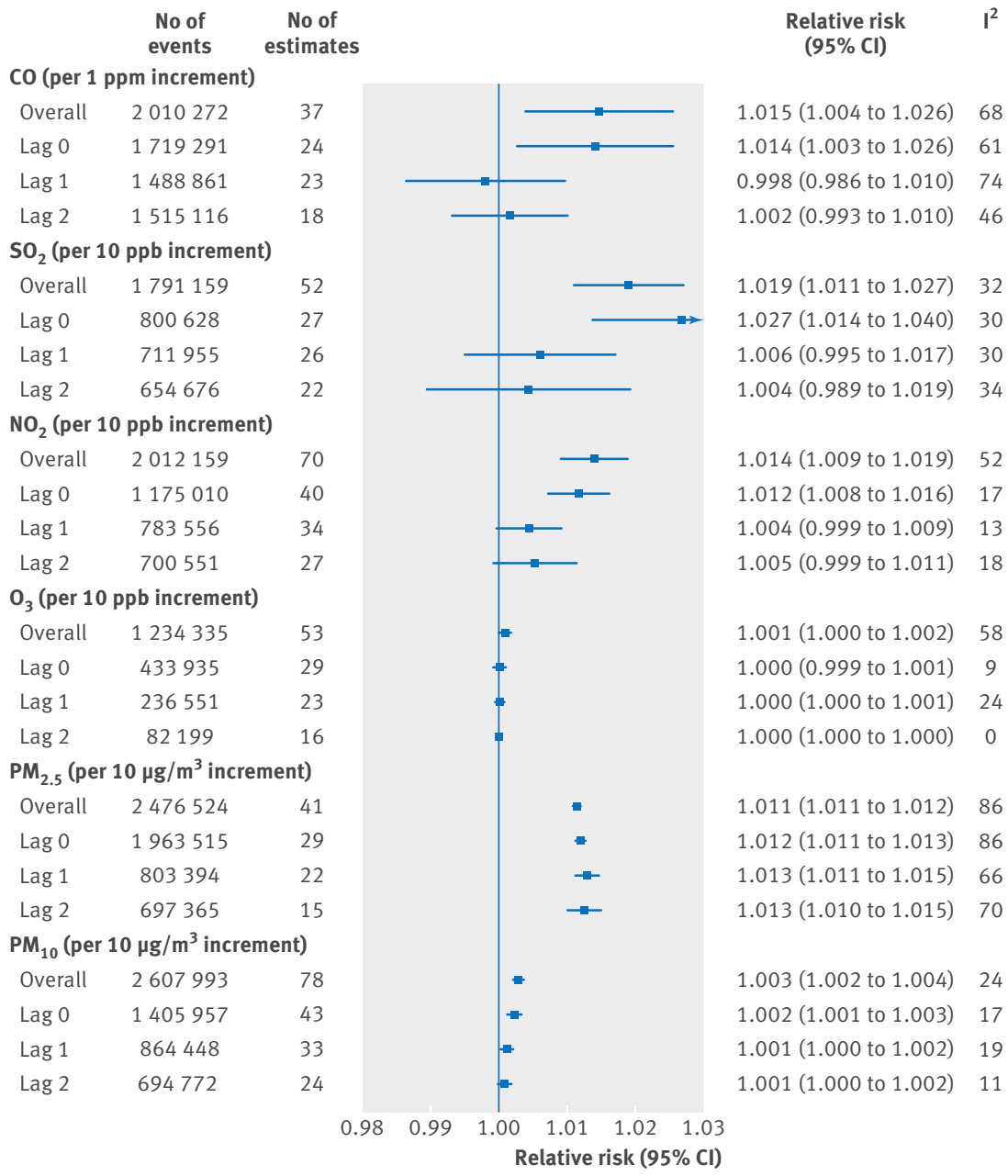

Fig 1 Association between gaseous and particulate air pollutants and admission for stroke or mortality from stroke stratified by time lag (days) for our analysis to account for heterogeneity both within and between studies. ${ }^{25}$ We conducted prespecified subgroup analysis by study design, age, sex, outcome, and type of stroke to explore any underlying source for heterogeneity.

We constructed funnel plots to examine publication bias (appendix 5) and assessed them for asymmetry using Egger's regression test. ${ }^{26}$ We then corrected for asymmetry using the trim and fill method, with adjusted relative risks and the number of studies adjusted presented for each pollutant. ${ }^{27}$

Summary statistics are presented as relative risk per given increment in pollutant concentration. The analysis was performed with comprehensive meta-analysis (Biostat, Englewood, NJ) and RStudio (RStudio 2013, version 0.98.501). Significance for pooled estimates was taken as a two sided $\mathrm{P}<0.05$.

\section{Results}

We assessed the abstracts of 2748 articles and reviewed 238 relevant studies in depth. Of these, we identified 103 that fulfilled the inclusion criteria (appendix 2 and 3). ${ }^{13} 1420-2328-3561-149$ Sixty nine studies used a time series design, 33 used a case crossover design, and one used both study designs incorporating over 6.2 million events across 28 countries (appendix 3 ). Twenty five (24\%) studies presented analyses stratified by type of stroke (haemorrhagic and ischaemic), though only a minority of studies reported on haemorrhagic strokes (15 studies, $15 \%)$. Most studies presented risk estimates for stroke defined from administrative databases using the ICD-9 and ICD-10 codes (appendix 4). Most studies adjusted for other meteorological parameters including time trends, seasonality, and temperature (appendix 4). Not all studies provided risk estimates across all pollutants (appendix 3).

Of the 103 studies that met the inclusion criteria, we excluded nine studies from meta-analysis. Of these nine studies, five presented estimates as a subset of the parent study and therefore only estimates from the parent study were included. ${ }^{28-32}$ Four studies were excluded as risks were presented per category of pollutant concentration rather than per unit increment, the increment was not defined, or the effect estimates were not presented as either relative risks or odds ratios. ${ }^{21}$ 33-35

There was a positive association between all gaseous and particulate air pollutants and admission to hospital for stroke or mortality from stroke, with the weakest association seen for ozone (fig 1). Individual forest plots for each of the pollutants are presented in appendix 6 .

\section{Particulate pollutants}

Both $\mathrm{PM}_{2.5}$ and $\mathrm{PM}_{10}$ were positively associated with admission to hospital for stroke or mortality from stroke, with a stronger association for $\mathrm{PM}_{2.5}$. The increase in relative risk was 1.011 (95\% confidence interval 1.011 to 1.012) per $10 \mu \mathrm{g} / \mathrm{m}^{3}$ increase in $\mathrm{PM}_{2.5}$ concentration (fig 1). The association between $\mathrm{PM}_{2.5}$ and stroke was evident on the day of the event (lag 0) and was present for up to two days (lag 2) before the event.

These associations persisted when we stratified by outcome (admission or death), sex, age ( $>65)$, or study design 
(fig 2 and appendix 7) for either $\mathrm{PM}_{25}$ or $\mathrm{PM}_{10}$. Few studies reported summary estimates by type of stroke, but when they were reported, the association for $\mathrm{PM}_{2.5}$ was 1.010 (95\% confidence interval 1.008 to $1.011 ; \mathrm{I}^{2}=69 \%$ ) for ischaemic stroke and 1.004 ( 0.978 to 1.029; $\mathrm{I}^{2}=14 \%$ ) for haemorrhagic stroke (appendix 7). Risks for ischaemic stroke and haemorrhagic stroke associated with $\mathrm{PM}_{10}$ exposure were comparable (1.002 ( 0.999 to $1.004 ; \mathrm{I}^{2}=23 \%$ ) and 1.002 (0.997 to $1.006 ; \mathrm{I}^{2}=0 \%$ ), respectively).

\section{Gaseous pollutants}

Nitrogen dioxide was the most commonly measured gaseous pollutant, with a 1.014 (95\% confidence interval 1.009 to 1.019 ) relative increase in risk of admission

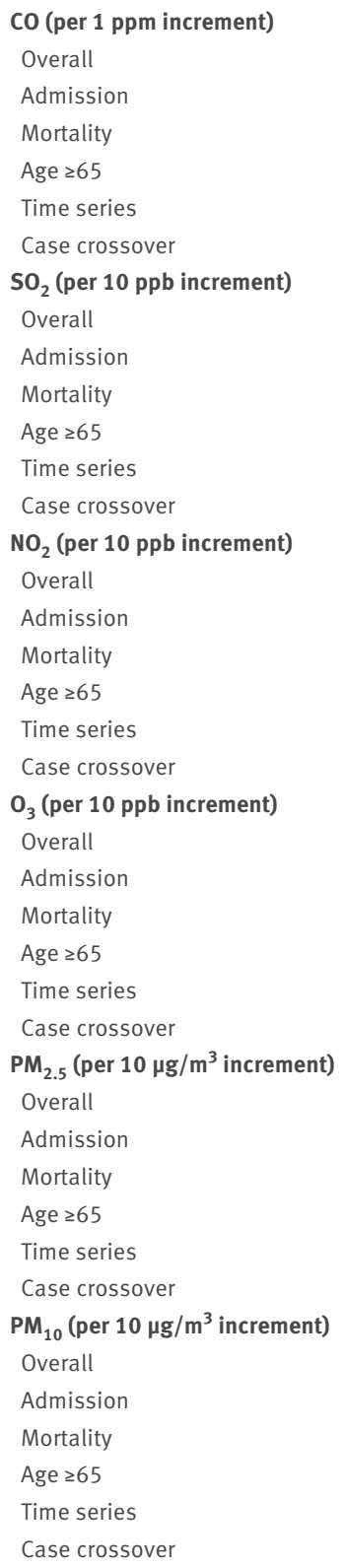

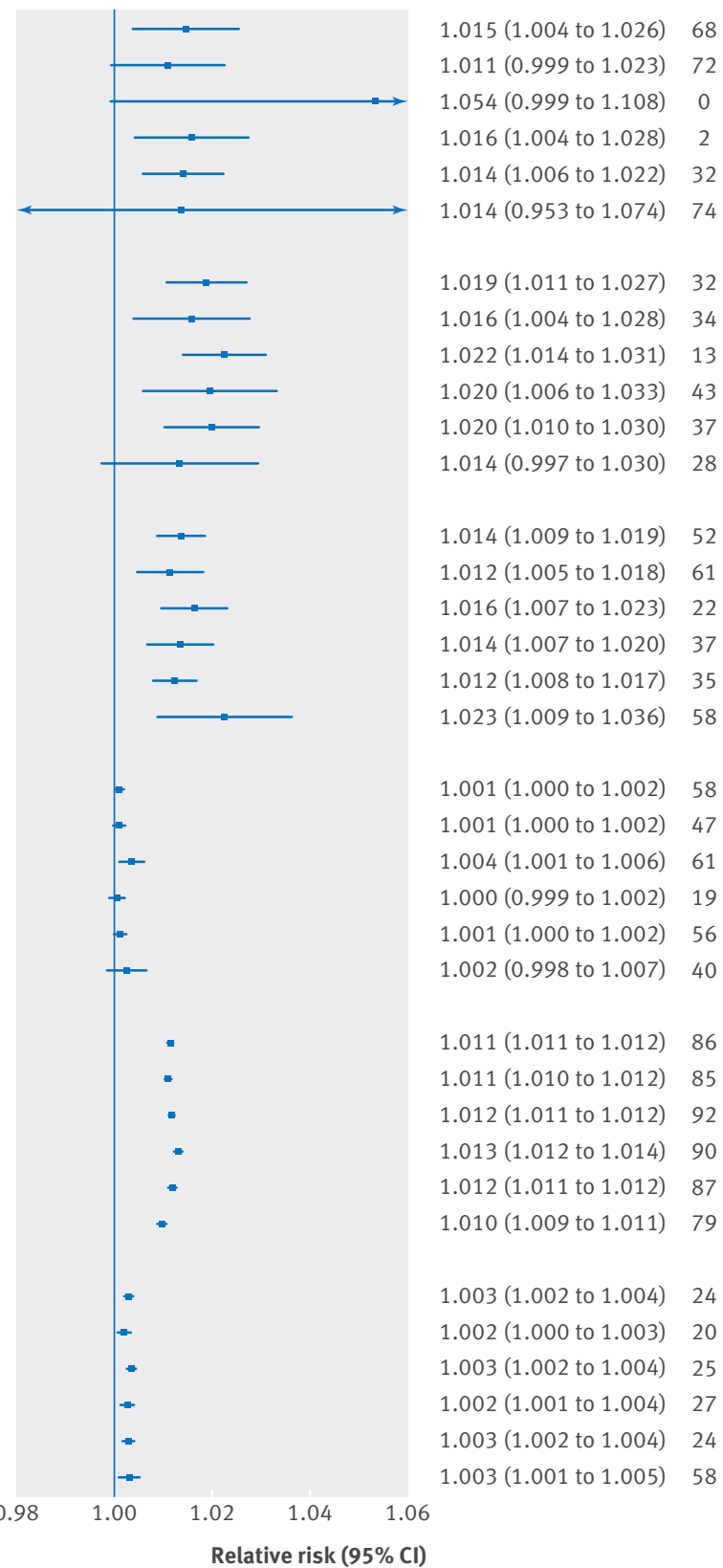

Fig 2 Associations across all gaseous and particulate air pollutants stratified by outcome, age, and study design to hospital for stroke or mortality from stroke per $10 \mathrm{ppb}$ increment across two million events (fig 1). Both sulphur dioxide (1.019 (1.011 to 1.027) per $10 \mathrm{ppb)}$ and carbon monoxide (1.015 (1.004 to 1.026) per $1 \mathrm{ppm}$ ) were also positively associated with admission and mortality. Ozone however, showed only a weak association (1.001 (1.000 to 1.002) per $10 \mathrm{ppb}$; fig 1).

These associations persisted when we stratified by outcome, age, and study design. All gaseous pollutants except ozone showed a positive and consistent relation with ischaemic stroke (appendix 7). Nitrogen dioxide exposure showed a consistent association with both ischaemic and haemorrhagic stroke (1.024 (95\% confidence interval 1.010 to $1.038, \mathrm{I}^{2}=56 \%$ ) and 1.024 (1.003 to $1.045 ; I^{2}=42 \%$ ), respectively; see appendix 7).

The association between gaseous pollutants and stroke was related to lag in exposure (days), with the strongest associations evident for pollutant concentrations on the day of the event (lag 0) and diminishing with longer lag periods (fig 1).

\section{Stratification by category of national income}

Most studies (80\%) originated from high income countries, with only $21(20 \%)$ originating from low or middle income countries. Both nitrogen dioxide and particulate matter $\left(\mathrm{PM}_{10}\right)$ were commonly measured across high and low to middle income countries. Studies for these pollutants originated from Latin America (including Brazil, Chile, and Mexico), South Africa, China, Thailand, Iran, and South Africa (fig 3). Most studies from low and middle income countries originated from mainland China (14 studies).

Pooled estimates from studies originating in low and middle income countries showed a stronger association than high income countries for nitrogen dioxide (1.019 (95\% confidence interval 1.011 to 1.027$) v 1.012$ (1.006 to 1.017)) and $\mathrm{PM}_{10}$ (1.004 (1.002 to 1.006) $v 1.002$ (1.001 to 1.003)) (fig 3). The median pollutant concentrations for nitrogen dioxide and $\mathrm{PM}_{10}$ were higher in low and middle income countries (median pollutant concentration $27.6 \mathrm{ppb}$ (interquartile range $23.8-29.6 \mathrm{ppb}$ ) for nitrogen dioxide and $50.2 \mu \mathrm{g} / \mathrm{m}^{3}\left(32.6-65.7 \mu \mathrm{g} / \mathrm{m}^{3}\right)$ for $\left.\mathrm{PM}_{10}\right)$ than in high income countries (median pollutant concentration 22.6 ppb (19.4-28.3 ppb) for nitrogen dioxide and $25.3 \mu \mathrm{g} / \mathrm{m}^{3}\left(23.8-29.6 \mu \mathrm{g} / \mathrm{m}^{3}\right)$ for $\left.\mathrm{PM}_{10}\right)$.

\section{Bias and heterogeneity}

There was no difference in our overall effect estimates when we removed studies at increased risk of bias (appendix 8). Publication bias (Egger's test for asymmetry $\mathrm{P}<0.05)$ was observed for all pollutants except sulphur dioxide and $\mathrm{PM}_{2.5}$ (table; appendix 4). Adjustment for asymmetry with the trim and fill method did not alter the effect direction but, as expected, did attenuate the effect size. We observed heterogeneity across all pollutants, and this was most evident with $\mathrm{PM}_{2.5}\left(\mathrm{I}^{2}=86 \%\right)$ and least evident with $\mathrm{PM}_{10}\left(\mathrm{I}^{2}=24 \%\right)$.

\section{Discussion}

In this systematic review and meta-analysis, we evaluated the effects of short term exposure to gaseous and 

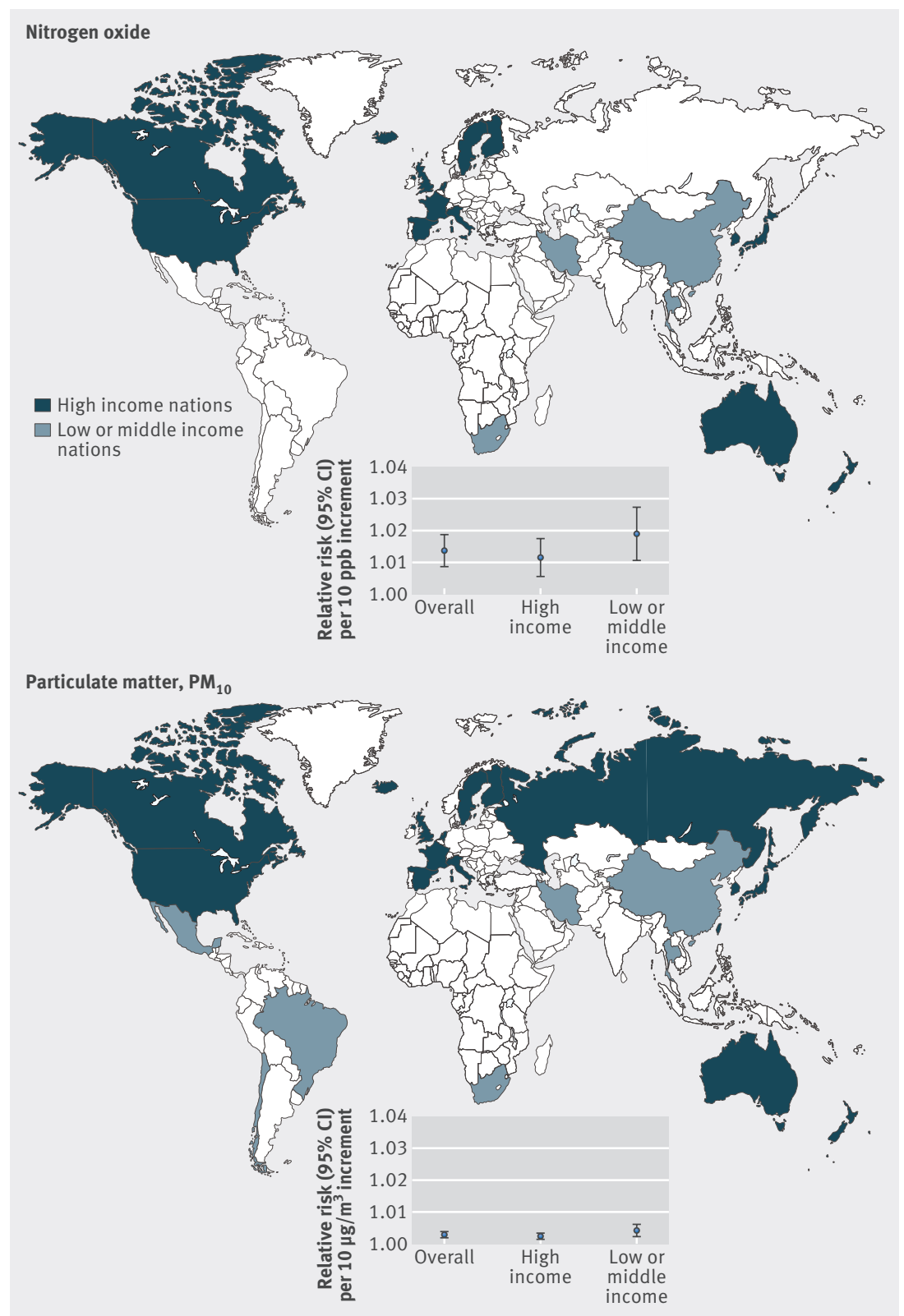

Fig 3 | Cartogram identifying association between nitrogen dioxide and particulate matter $\left(\mathrm{PM}_{10}\right)$ and admission to hospital for stroke or mortality from stroke in countries stratified as high and low to middle income suggest that improvements in air quality could reduce the burden of stroke.

\section{Evidence of short term exposure to air pollution and stroke}

Over the past three decades, epidemiological studies including pooled analyses have shown that cardiac, rather than pulmonary, disease is the primary cause of morbidity and mortality associated with exposure to air pollution. ${ }^{36}$ Long term exposure studies have already shown strong associations between air pollution and stroke. ${ }^{37-39}$ While the short term effects of air pollution on cardiac disease, including heart failure and myocardial infarction, have received much attention, it is less certain whether acute exposure to air pollution is a trigger for cerebrovascular disease, especially stroke. ${ }^{3411}$ This is partly because the results of many short term exposure studies evaluating the effect of air pollution on stroke have been inconclusive, reflecting both the nature of the condition and the size of individual studies. ${ }^{36}$ Recently meta-analyses, including 12 and 45 studies, reported an association between particulate air pollution and stroke..$^{40-43}$ To our knowledge, our study is the first comprehensive prespecified pooled analysis to examine the short term effects after exposure to gaseous or particulate air pollution and admission to hospital for stroke or mortality from stroke across both time series and case crossover study designs.

Particulate matter and gaseous pollutants both showed a strong temporal relation with mortality from stroke and admission to hospital for stroke. The lag effects of exposure and stroke have to be interpreted with caution. Unlike other cardiac conditions such as acute myocardial infarction, decompensated heart failure, and sudden cardiac death, the timing of onset of stroke symptoms and subsequent admission to hospital or mortality might differ substantially. 44 Lokken and colleagues showed that in cases of acute ischaemic stroke, onset of symptoms occurred at a median of one calendar day before admission, and this delay in presentation is likely to underestimate the overall association between exposure to pollutant and stroke. ${ }^{44}$

\section{Aetiology of stroke and exposure to air pollution}

While our analysis showed consistent associations for ischaemic stroke and air pollution, the association for haemorrhagic stroke was more variable with larger imprecision. Our results were similar to those from a smaller meta-analysis that showed identical patterns with type of stroke and exposure to $\mathrm{PM}_{2.5}$ and $\mathrm{PM}_{10}{ }^{41}$ While haemorrhagic and ischaemic stroke share similar risk factors and have a similar clinical presentation, they are different clinical entities. ${ }^{45}$ Heterogeneity in the association between air pollution and stroke subtype might be caused by many factors. Firstly, the mechanisms linking exposure to air pollution and haemorrhagic stroke might differ for ischaemic stroke. Secondly, there were fewer estimates for haemorrhagic stroke, reflecting the lower incidence of this subtype, and therefore wider confidence intervals for these 


\begin{tabular}{|c|c|c|c|c|c|c|}
\hline \multicolumn{7}{|c|}{ Pollutant concentrations and assessment for publication bias stratified by gaseous and particulate air pollutants } \\
\hline & \multicolumn{4}{|l|}{ Gaseous pollutants } & \multicolumn{2}{|l|}{ Particulate matter } \\
\hline & $\begin{array}{l}\text { Carbon monoxide } \\
(\mathrm{ppm})\end{array}$ & $\begin{array}{l}\text { Nitrogen dioxide } \\
(\mathrm{ppb})\end{array}$ & $\begin{array}{l}\text { Sulphur dioxide } \\
\text { (ppb) }\end{array}$ & Ozone (ppb) & $2.5\left(\mu \mathrm{g} / \mathrm{m}^{3}\right)$ & $\mathrm{PM}_{10}\left(\mu \mathrm{g} / \mathrm{m}^{3}\right)$ \\
\hline Increment & 1 & 10 & 10 & 10 & 10 & 10 \\
\hline No of estimates & 37 & 70 & 52 & 53 & 41 & 78 \\
\hline \multicolumn{7}{|l|}{ Pollutant concentration: } \\
\hline Median (IQR) & $0.8(0.7-1.3)$ & $24.4(17.0-30.1)$ & $6.2(2.6-10.1)$ & $24.2(18.9-31.7)$ & $15.7(8.7-23.6)$ & $35.3(25.6-51.6)$ \\
\hline Range (min-max) & $0.3-5.5$ & $8.1-44.0$ & $1.1-30.2$ & $12.3-53.9$ & $5.8-34.3$ & $13-187.1$ \\
\hline \multicolumn{7}{|l|}{ Publication bias: } \\
\hline Egger regression test $\mathrm{P}$ value & 0.070 & 0.036 & 0.098 & 0.014 & 0.670 & $<0.001$ \\
\hline $\operatorname{RR}(95 \% \mathrm{Cl})^{*}$ & $1.015(1.004$ to 1.026$)$ & 1.014 (1.009 to 1.019$)$ & 1.019 (1.011 to 1.027$)$ & $1.001(1.000$ to 1.002$)$ & 1.011 (1.011 to 1.012) & $1.003(1.002$ to 1.004$)$ \\
\hline Adjusted RR $(95 \%$ Cl)† & 1.015 (1.004 to 1.027$)$ & $1.014(1.009$ to 1.020$)$ & 1.017 (1.009 to 1.024) & 1.001 (1.000 to 1.002$)$ & 1.011 (1.011 to 1.012$)$ & 1.001 (1.001 to 1.002$)$ \\
\hline No of studies adjusted & 8 & 6 & 8 & 7 & 3 & 24 \\
\hline
\end{tabular}

*Relative risk derived from pooled analysis of studies.

tRelative risk adjusted for publication bias with trim and fill method.

$\mathrm{ppm}=$ parts per million; $\mathrm{ppb}=$ parts per billion.

estimates. Finally, misclassification of stroke subtype in those studies from countries with limited availability of medical imaging might have contributed to some of the observed heterogeneity.42 46

\section{Particulate pollution and stroke}

Exposure to $\mathrm{PM}_{10}$ showed weaker associations with admission to hospital for stroke or mortality from stroke than $\mathrm{PM}_{2.5}$, consistent with observations from other meta-analyses for stroke $\mathrm{e}^{42}$ and acute myocardial infarction. ${ }^{3}$ This could reflect differences in particle size, with larger particles more likely to exert local pulmonary effects whereas fine or ultrafine particles $\left(\mathrm{PM}_{2.5}\right)$ or gaseous pollutants could cause additional systemic cardiovascular effects. ${ }^{36}$ In contrast, the adverse effect of larger particles in patients with heart failure was more striking, possibly reflecting indirect biological pathways such as the adverse effect of sympathetic nervous activation on the failing heart. ${ }^{46} \mathrm{We}$ noticed greater heterogeneity for $\mathrm{PM}_{2.5}$ than for $\mathrm{PM}_{10}$. These differences in heterogeneity persisted after subgroup analysis and could reflect variation in study design. We were able to meta-analyse twice as many estimates for $\mathrm{PM}_{10}$ than for $\mathrm{PM}_{2.5}$, with an overall less marked but more consistent effect of exposure on stroke with $\mathrm{PM}_{10}$. There are several biologically plausible reasons for this. While there is a close correlation between $\mathrm{PM}_{2.5}$ and $\mathrm{PM}_{10}$ concentrations, epidemiological studies have shown that the association between $\mathrm{PM}_{10}$ and acute cardiovascular events is primarily driven by the $\mathrm{PM}_{2.5}$ fraction. ${ }^{47}$ This fraction is enriched with ultrafine particles derived from the combustion of fossil fuels, which toxicology studies have suggested are the most potent component of particulate matter. ${ }^{48}$ These particles are potentially small enough to translocate from the lungs into the circulation and are therefore perhaps more likely to trigger acute cardiovascular episodes. ${ }^{49}$ Interestingly, all three gaseous pollutants derived from combustion (nitrogen dioxide, sulphur dioxide, and carbon monoxide) were associated with stroke, and this was consistent with reported associations with admission for heart failure and acute myocardial infarction. ${ }^{3436}$
Possible mechanisms explaining relation between stroke and air pollution

Several large cohort studies have shown a positive association between long term exposure to ambient air pollution and coronary and cerebrovascular events. ${ }^{50-52}$ Staffogia and colleagues showed that even in high income countries, where annual mean air pollution concentrations meet current international standards, small increases in $\mathrm{PM}_{2.5}$ were associated with a $19 \%$ increase in the risk of cerebrovascular disease, including both ischaemic and haemorrhagic events. ${ }^{51}$ Long term exposures to $\mathrm{PM}_{2.5}$ accelerate carotid atherosclerosis. ${ }^{53}$ The underlying pathophysiological mechanisms after acute exposure to air pollutants in triggering stroke, however, remain unclear and might differ for haemorrhagic and ischaemic stroke. ${ }^{12}$ Previous controlled exposure studies have shown that air pollution can adversely affect the vascular endothelium and increase activity of the sympathetic nervous system, resulting in vasoconstriction, increases in blood pressure, ischaemia, and risk of thrombosis. ${ }^{554}$ Indeed, even minor increases in $\mathrm{PM}_{2.5}$ concentrations are associated with changes in cerebrovascular haemodynamics, including increased cerebrovascular resistance and reduced cerebral blood flow. ${ }^{55}$ Another potentially important effect of air pollution that is pertinent to stroke is the risk of atrial arrhythmias, which could predispose to thromboembolic events. It is plausible that the association between short term exposure to air pollution and cerebrovascular events are a result of these important mechanistic pathways.

\section{Air pollution and stroke by income of nation}

Most of the studies used to derive our pooled estimates originated from high income countries. The smaller number of studies from low and middle income countries is probably a result of less cohesive policies on air quality, inadequate environmental monitoring, and less robust disease surveillance. ${ }^{56}$ This is particularly concerning as it is these countries that bear a disproportionate burden of the global morbidity and mortality from stroke. ${ }^{12}$ More concerning are the trends for cerebrovascular disease, where the incidence is falling by 
$12 \%$ in high income countries and increasing by $12 \%$ in low and middle income countries. ${ }^{10}$ Urban cities in low and middle income countries not only experience high levels of ambient air pollution but also have larger daily fluctuations in levels. ${ }^{57} 58$ Our pooled estimates stratified by region showed larger associations in low and middle income countries than in high income countries. Our estimates from low and middle income countries, however, predominantly come from East Asia, mainly mainland China followed by Latin America, South East Asia, and South Africa. There still remains a paucity of data from other highly populated regions including the Indian subcontinent and north and central Africa.

\section{Limitations}

Several limitations of our study should be considered. Firstly, unlike other cardiac conditions such as myocardial infarction, case definition for stroke, especially when administrative data are used, might be less reliable. ${ }^{59} 60$ Secondly, many studies measured concentrations of air pollution at remote monitoring sites, and it is therefore likely there will be some degree of misclassification of exposure. While there might be good correlations in measurements between pollutant concentrations at patient specific locations compared with those measured at remote stations, it is likely that highly urbanised city centres will not only experience higher concentrations but also greater fluctuations in concentrations. Therefore such ecological studies might underestimate the overall associations reported for stroke and air pollution. Thirdly, we did not have access to primary data and were not able to determine whether patients were included across multiple studies if there was partial temporal overlap between studies from the same geographical location. We did, however, exclude studies with complete geographical and temporal overlap during meta-analysis. Finally, we noticed significant heterogeneity (except for $\mathrm{PM}_{10}$ ) across all pollutants. This could be because of systemic differences in the baseline characteristics of the underlying population in addition to misclassification of both the measurement of pollutant and outcome. Our sensitivity analysis after exclusion of studies with a high risk of bias, however, showed similar results to the overall effect estimates.

\section{Conclusion}

Stroke remains the second most common cause of death and third most important cause of disability worldwide. Over the past 20 years many environmental studies have evaluated the association between outdoor air pollution and stroke, with varying conclusions. Our pooled estimates now show a marked and close association between exposure to pollutants and adverse stroke outcomes. Only a few studies originated from low or middle income countries and yet these countries experience the highest levels of air pollution and bear a disproportionate burden of global stroke mortality and morbidity. Public and environmental health policies that aim to reduce air pollution levels might reduce the burden of stroke.
Contributors: ASVS and KKL contributed equally. ASVS conceived and designed the study. ASVS, KKL, and AH acquired the data. ASVS, KKL, DM, DEN, and NLM analysed and interpreted the data. ASVS, DEN, DM, and NLM drafted the initial manuscript. All authors made critical revisions of the manuscript for important intellectual content and approved the final version of the report. ASVS is guarantor

Funding: This study was funded by a British Heart Foundation programme grant (RG/10/9/28286). ASVS, DEN, and NLM were supported by a British Heart Foundation clinical research scholarship (SS/CH/09/002), intermediate fellowship (FS/10/024/28266), chair award (CH/09/002), and programme grant (RG/10/9/28286), respectively. The sponsor of the study had no role in study design, data collection, data analysis, data interpretation, or writing of the report. Competing interests: All authors have completed the ICMJE uniform disclosure form at www.icmje.org/coi_disclosure.pdf and declare: no financial relationships with any organisations that might have an interest in the submitted work in the previous three years; no other relationships or activities that could appear to have influenced the submitted work.

Ethical approval: Not required.

Data sharing: No additional data available.

Transparency: The lead author, (the manuscript's guarantor), affirms that the manuscript is an honest, accurate, and transparent account of the study being reported; that no important aspects of the study have been omitted; and that any discrepancies from the study as planned (and, if relevant, registered) have been explained.

This is an Open Access article distributed in accordance with the terms of the Creative Commons Attribution (CC BY 4.0) license, which permits others to distribute, remix, adapt and build upon this work, for commercial use, provided the original work is properly cited. See: http://creativecommons.org/licenses/by/4.0/.

Brook RD, Rajagopalan S, Pope CA, 3rd, et al. Particulate matter air pollution and cardiovascular disease: an update to the scientific statement from the American Heart Association. Circulation 2010;121:2331-78.

2 Lim SS, VOS T, Flaxman AD, et al. A comparative risk assessment of burden of disease and injury attributable to 67 risk factors and risk factor clusters in 21 regions, 1990-2010: a systematic analysis for the Global Burden of Disease Study 2010. Lancet 2012:380:2224-60.

3 Mustafic $\mathrm{H}$, Jabre P, Caussin C, et al. Main air pollutants and myocardial infarction: a systematic review and meta-analysis. IAMA 2012:307:713-21.

4 Shah AS, Langrish JP, Nair H, et al. Global association of air pollution and heart failure: a systematic review and meta-analysis. Lancet 2013;382:1039-48.

5 Mills NL, Miller MR, Lucking AJ, et al. Combustion-derived nanoparticulate induces the adverse vascular effects of diese exhaust inhalation. Eur Heart J 2011;32:2660-71.

6 Brook RD, Brook JR, Urch B, et al. Inhalation of fine particulate air pollution and ozone causes acute arterial vasoconstriction in healthy adults. Circulation 2002;105:1534-6.

7 Lundback M, Mills NL, Lucking A, et al. Experimental exposure to diesel exhaust increases arterial stiffness in man. Part Fibre Toxicol 2009;6:7.

8 Lucking AJ, Lundback M, Mills NL, et al. Diesel exhaust inhalation increases thrombus formation in man. Eur Heart / 2008:29:3043-51.

9 Lozano R, Naghavi M, Foreman K, et al. Global and regional mortality from 235 causes of death for 20 age groups in 1990 and 2010: a systematic analysis for the Global Burden of Disease Study 2010. Lancet 2012;380:2095-128.

10 Feigin VL, Forouzanfar MH, Krishnamurthi R, et al. Global and regional burden of stroke during 1990-2010: findings from the Global Burden of Disease Study 2010. Lancet 2014:383:245-54.

11 Mateen FJ, Brook RD. Air pollution as an emerging global risk factor for stroke. JAMA 2011;305:1240-1.

12 O'Donnell MJ, Xavier D, Liu L, et al. Risk factors for ischaemic and intracerebral haemorrhagic stroke in 22 countries (the INTERSTROKE study): a case-control study. Lancet 2010;376:112-23.

13 Wellenius GA, Burger MR, Coull BA, et al. Ambient air pollution and the risk of acute ischemic stroke. Arch Intern Med 2012;172:229-34

14 Sunyer J, Ballester F, Tertre AL, et al. The association of daily sulfur dioxide air pollution levels with hospital admissions for cardiovascular diseases in Europe (The Aphea-II study). Eur Heart J 2003;24:752-60.

15 Shah AS, Newby DE, Mills NL. Potential link between ozone and recurrent stroke. Heart 2010:96:1953-4.

16 Maclure. The case-crossover design: a method for studying transient effects on the risk of acute events. Am J Epidemiology 1991;133:144-53. 
17 Lumley TL, D. Bias in the case-crossover design: implications for studies of air pollution. Environmetrics 2000;11:689-704.

18 Fung $\mathrm{KY}$, Krewski D, Chen Y, et al. Comparison of time series and case-crossover analyses of air pollution and hospital admission data. Int J Epidemiol 2003;32:1064-70.

19 Moolgavkar SH. Air pollution and daily mortality in three U.S. counties. Environ Health Perspect 2000;108:777-84.

20 Burnett RT, Smith-Doiron M, Stieb D, et al. Effects of particulate and gaseous air pollution on cardiorespiratory hospitalizations. Arch Environ Health 1999:54:130-9.

21 Low RB, Bielory L, Qureshi Al, et al. The relation of stroke admissions to recent weather, airborne allergens, air pollution, seasons, upper respiratory infections, and asthma incidence, September 11, 2001, and day of the week. Stroke 2006;37:951-7.

22 Pönkä A, Virtanen M. Low-level air pollution and hospital admissions for cardiac and cerebrovascular diseases in Helsinki. Am J Public Health 1996:86:1273-80.

23 Linn WS, Szlachcic Y, Gong H Jr, et al. Air pollution and daily hospital admissions in metropolitan Los Angeles. Environ Health Perspect 2000:108:427-34

24 World Bank. How we classify countries. http://data.worldbank.org/ about/country-classifications.

25 Kelley G, Kelley K. Statistical models for meta-analysis: a brief tutorial. World J Methodol 2012;2:27-32.

26 Egger M, Davey Smith G, Schneider M, et al. Bias in meta-analysis detected by a simple, graphical test. BMJ 1997;315:629-34.

27 Duval S, Tweedie R. Trim and fill: a simple funnel-plot-based method of testing and adjusting for publication bias in meta-analysis. Biometrics 2000;56:455-63.

28 Qian Z, He Q, Lin HM, et al. Short-term effects of gaseous pollutants on cause-specific mortality in Wuhan, China. J Air Waste Manag Assoc 2007:57:785-93.

29 Qian Z, He Q, Lin HM, et al. Association of daily cause-specific mortality with ambient particle air pollution in Wuhan, China. Environ Res 2007;105:380-9.

30 Qian Z, He Q, Lin HM, et al. Exploring uncertainty of the change from ICD-9 to ICD-10 on acute mortality effects of air pollution. Environ Int 2008;34:248-53.

31 Qian Z, He Q, Lin HM, et al. High temperatures enhanced acute mortality effects of ambient particle pollution in the "oven" city of Wuhan, China. Environ Health Perspect 2008;116:1172-8.

32 Qian Z, Lin HM, Stewart WF, et al. Seasonal pattern of the acute mortality effects of air pollution. J Air Waste Manag Assoc 2010;60:481-8.

33 Vidale S, Bonanomi A Guidotti M et al Air pollution positively correlates with daily stroke admission and in hospital mortality: a study in the urban area of Como, Italy. Neurol Sci 2010;31:179-82.

34 Oudin A, Stromberg U, Jakobsson K, et al. Estimation of short-term effects of air pollution on stroke hospital admissions in southern Sweden. Neuroepidemiology 2010;34:131-42.

35 Nabavi SM, Jafari B, Jalali MS, et al. Environmental air pollution and acute cerebrovascular complications: an ecologic study in Tehran, Iran. Int J Prev Med 2012;3:723-9.

36 Donaldson K, Duffin R, Langrish JP, et al. Nanoparticles and the cardiovascular system: a critical review. Nanomedicine (Lond) 2013;8:403-23.

37 Miller KA, Siscovick DS, Sheppard L, et al. Long-term exposure to air pollution and incidence of cardiovascular events in women. $N$ Engl/ Med 2007:356:447-58.

38 Dockery DW, Pope CA, 3rd, Xu X, et al. An association between air pollution and mortality in six U.S. cities. N Engl J Med 1993;329:1753-9.

39 Pope CA, Burnett RT, Krewski D, et al. Cardiovascular mortality and exposure to airborne fine particulate matter and cigarette smoke: shape of the exposure-response relationship. Circulation 2009; 120:941-48.

40 Atkinson RW, Kang S, Anderson HR, et al. Epidemiological time series studies of PM2.5 and daily mortality and hospital admissions: a systematic review and meta-analysis. Thorax 2014;69:660-5.

41 Yu XB, Su JW, Li XY, et al. Short-term effects of particulate matter on stroke attack: meta-regression and meta-analyses. PLoS One 2014;9:e95682

42 Wang Y, Eliot MN, Wellenius GA. Short-term changes in ambient particulate matter and risk of stroke: a systematic review and meta-analysis. J Am Heart Assoc 2014;3; e000983.

43 Li XY, Yu XB, Liang WW, et al. Meta-analysis of association between particulate matter and stroke attack. CNS Neurosci Ther 2012;18:501-8

44 Lokken RP, Wellenius GA, Coull BA, et al. Air pollution and risk of stroke: underestimation of effect due to misclassification of time of event onset. Epidemiology 2009;20:137-42.

45 O’Donnell M], Xavier D, Liu L, et al. Risk factors for ischaemic and intracerebral haemorrhagic stroke in 22 countries (the INTERSTROKE study): a case-control study. Lancet 2010;376:112-23.

46 Johnsen SP, Overvad K, Sorensen HT, et al. Predictive value of stroke and transient ischemic attack discharge diagnoses in the Danish National Registry of Patients. / Clin Epidemiol 2002;55:602-7.
47 Samoli E, Stafoggia M, Rodopoulou S, et al. Associations between fine and coarse particles and mortality in Mediterranean cities: results from the MED-PARTICLES project. Environ Health Perspect 2013;121:932-8.

48 Mills NL, Donaldson K, Hadoke PW, et al. Adverse cardiovascular effects of air pollution. Nat Clin Pract Cardiovasc Med 2009;6:36-44.

49 Donaldson K, Duffin R, Langrish JP, et al. Nanoparticles and the cardiovascular system: a critical review. Nanomedicine (Lond) 2013;8:403-23.

50 Beelen R, Raaschou-Nielsen O, Stafoggia M, et al. Effects of long-term exposure to air pollution on natural-cause mortality: an analysis of 22 European cohorts within the multicentre ESCAPE project. Lancet 2014:383:785-95.

51 Stafoggia M, Cesaroni G, Peters A, et al. Long-term exposure to ambient air pollution and incidence of cerebrovascular events: results from 11 European cohorts within the ESCAPE project. Environ Health Perspect 2014:122:919-25.

52 Cesaroni G, Forastiere F, Stafoggia M, et al. Long term exposure to ambient air pollution and incidence of acute coronary events: prospective cohort study and meta-analysis in 11 European cohorts from the ESCAPE project. BM/ 2014;348:f7412.

53 Adar SD, Sheppard L, Vedal S, et al. Fine particulate air pollution and the progression of carotid intima-medial thickness: a prospective cohort study from the multi-ethnic study of atherosclerosis and air pollution. PLoS Med 2013;10:e1001430.

54 Lucking AJ, Lundback M, Barath SL, et al. Particle traps prevent adverse vascular and prothrombotic effects of diesel engine exhaust inhalation in men. Circulation 2011;123:1721-8

55 Wellenius GA, Boyle LD, Wilker EH, et al. Ambient fine particulate matter alters cerebral hemodynamics in the elderly. Stroke 2013:44:1532-6.

56 Briggs D. Environmental pollution and the global burden of disease. Br Med Bull 2003;68:1-24.

57 Langrish JP, LiX, Wang S, et al. Reducing personal exposure to particulate air pollution improves cardiovascular health in patients with coronary heart disease. Environ Health Perspect 2012;120:367-72

58 Guttikunda S. Photochemistry of air pollution in Delhi, India. Working Paper Series SIM No 25, 2009. http://urbanemissions.info/ sim-series-25.html.

59 Goldstein LB. Accuracy of ICD-9-CM coding for the identification of patients with acute ischemic stroke: effect of modifier codes. Stroke 1998;29:1602-4.

60 McCormick N, Lacaille D, Bhole V, et al. Validity of myocardial infarction diagnoses in administrative databases: a systematic review. PLoS One 2014;9:e92286.

61 Wordley J, Walters S, Ayres JG. Short term variations in hospital admissions and mortality and particulate air pollution. Occup Environ Med 1997;54:108-16.

62 Poloniecki JD, Atkinson RW, de Leon AP, et al. Daily time series for cardiovascular hospital admissions and previous day's air pollution in London, UK. Occup Environ Med 1997;54:535-40.

63 Wong CM, Ma S, Hedley AJ, et al. Does ozone have any effect on daily hospital admissions for circulatory diseases? J Epidemiol Community Health 1999:53:580-1.

64 Wong TW, Lau TS, Yu TS, et al. Air pollution and hospital admissions for respiratory and cardiovascular diseases in Hong Kong. Occup Environ Med 1999:56:679-83.

65 Moolgavkar SH. Air pollution and hospital admissions for diseases of the circulatory system in three U.S. metropolitan areas. J Air Waste Manag Assoc 2000;50:1199-206.

66 Lippmann M, Ito K, Nádas A, et al. Association of particulate matter components with daily mortality and morbidity in urban populations. Res Rep Health Eff Inst 2000;95:5-82.

67 Hoek G, Brunekreef B, Fischer P et al. The association between air pollution and heart failure, arrhythmia, embolism, thrombosis, and other cardiovascular causes of death in a time series study. Epidemiology 2001;12:355-7.

68 Ballester F, Tenias JM, Perez-Hoyos S. Air pollution and emergency hospital admissions for cardiovascular diseases in Valencia, Spain. I Epidemiol Community Health 2001;55:57-65.

69 Anderson HR, Bremner SA, Atkinson RW, et al. Particulate matter and daily mortality and hospital admissions in the west midlands conurbation of the United Kingdom: associations with fine and coarse particles, black smoke and sulphate. Occup Environ Med 2001;58:504-10.

70 Hong YC, Lee JT, Kim H, et al. Effects of air pollutants on acute stroke mortality. Environ Health Perspect 2002;110:187-91.

71 Wong TW, Tam WS, Yu TS, et al. Associations between daily mortalities from respiratory and cardiovascular diseases and air pollution in Hong Kong, China. Occup Environ Med 2002;59:30-5.

72 Le Tertre A, Medina S, Samoli E, et al. Short-term effects of particulate air pollution on cardiovascular diseases in eight European cities. J Epidemiol Comm unity Health 2002;56:773-9.

73 Hong YC, Lee JT, Kim H, et al. Air pollution: a new risk factor in ischemic stroke mortality. Stroke 2002:33:2165-9. 
$74 \mathrm{Kan} \mathrm{H}$, Jia J, Chen B. Acute stroke mortality and air pollution: new evidence from Shanghai, China. J Occup Health 2003:45:321-3.

$75 \mathrm{Kim} \mathrm{H}$, Kim Y, Hong YC. The lag-effect pattern in the relationship of particulate air pollution to daily mortality in Seoul, Korea. Int J Biometeorol 2003;48:25-30.

76 Tsai SS, Goggins WB, Chiu HF, et al. Evidence for an association between air pollution and daily stroke admissions in Kaohsiung, Taiwan. Stroke 2003;34:2612-6.

77 Metzger KB, Tolbert PE, Klein M, et al. Ambient air pollution and cardiovascular emergency department visits. Epidemiology 2004; 15:46-56

78 Wellenius GA, Schwartz J, Mittleman MA. Air pollution and hospital admissions for ischemic and hemorrhagic stroke among medicare beneficiaries. Stroke 2005;36:2549-53.

79 Jalaludin B, Morgan G, Lincoln D, et al. Associations between ambient air pollution and daily emergency department attendances fo cardiovascular disease in the elderly (65+ years), Sydney, Australia. J Expo Sci Environ Epidemiol 2006;16:225-37.

80 Barnett AG, Williams GM, Schwartz J, et al. The effects of air pollution on hospitalizations for cardiovascular disease in elderly people in Australian and New Zealand cities. Environ Health Perspect 2006;114:1018-23.

81 Villeneuve PJ, Chen L, Stieb D, et al. Associations between outdoor air pollution and emergency department visits for stroke in Edmonton, Canada. Eur J Epidemiol 2006;21:689-700.

82 Chan CC, Chuang KJ, Chien LC, et al. Urban air pollution and emergency admissions for cerebrovascular diseases in Taipei, Taiwan. Eur Heart J 2006;27:1238-44.

83 Zeka A, Zanobetti A, Schwartz J. Individual-level modifiers of the effects of particulate matter on daily mortality. Am J Epidemiol 2006;163:849-59.

84 Dominici F, Peng RD, Bell ML, et al. Fine particulate air pollution and hospital admission for cardiovascular and respiratory diseases. JAMA 2006;295:1127-34

85 Kettunen J, Lanki T, Tiittanen P, et al. Associations of fine and ultrafine particulate air pollution with stroke mortality in an area of low air pollution levels. Stroke 2007:38:918-22.

86 Larrieu S, Jusot JF, Blanchard M, et al. Short term effects of air pollution on hospitalizations for cardiovascular diseases in eight French cities: the PSAS program. Sci Total Environ 2007;387:105-12.

87 Henrotin JB, Besancenot JP, Bejot Y, et al. Short-term effects of ozone air pollution on ischaemic stroke occurrence: a case-crossover analysis from a 10-year population-based study in Dijon, France. Occup Environ Med 2007;64:439-45.

88 Neuberger M, Rabczenko D, Moshammer H. Extended effects of air pollution on cardiopulmonary mortality in Vienna. Atmosph Environ 2007:41:8549-56.

89 Yamazaki S, Nitta H, Ono M, et al. Intracerebral haemorrhage associated with hourly concentration of ambient particulate matter: case-crossover analysis. Occup Environ Med 2007;64:17-24.

90 Franklin M, Zeka A, Schwartz J. Association between PM2.5 and all-cause and specific-cause mortality in 27 US communities. J Expo Sci Environ Epidemiol 2007;17:279-87.

91 Peel JL, Metzger KB, Klein M, et al. Ambient air pollution and cardiovascular emergency department visits in potentially sensitive groups. Am J Epidemiol 2007;165:625-33.

92 Szyszkowicz M. Ambient air pollution and daily emergency department visits for ischemic stroke in Edmonton, Canada. Int Occup Med Environ Health 2008;21:295-300.

93 Forastiere F, Stafoggia M, Berti G, et al. Particulate matter and daily mortality: a case-crossover analysis of individual effect modifiers. Epidemiology 2008;19:571-80.

94 Bell ML, Levy JK, Lin Z. The effect of sandstorms and air pollution on cause-specific hospital admissions in Taipei, Taiwan. Occup Environ Med 2008;65:104-11.

95 Lisabeth LD, Escobar JD, Dvonch JT, et al. Ambient air pollution and risk for ischemic stroke and transient ischemic attack. Ann Neurol 2008;64:53-9.

96 Franklin M, Koutrakis P, Schwartz P. The role of particle composition on the association between PM2.5 and mortality. Epidemiology 2008;19:680-9.

97 Halonen Jl, Lanki T, Yli-Tuomi T, et al. Particulate air pollution and acute cardiorespiratory hospital admissions and mortality among the elderly. Epidemiology 2009;20:143-53.

98 Halonen JI, Lanki T, Tiittanen P, et al. Ozone and cause-specific cardiorespiratory morbidity and mortality. J Epidemiol Community Health 2010;64:814-20.

99 Haley VB, Talbot TO, Felton HD. Surveillance of the short-term impact of fine particle air pollution on cardiovascular disease hospitalizations in New York State. Environ Health 2009;8:42.

100 Zanobetti A, Franklin M, Koutrakis P, et al. Fine particulate air pollution and its components in association with cause-specific emergency admissions. Environ Health 2009;8:58

101 Bell ML, Peng RD, Dominici F, et al. Emergency hospital admissions for cardiovascular diseases and ambient levels of carbon monoxide: results for 126 United States urban counties, 1999-2005. Circulation 2009;120:949-55.

102 Morgan G, Sheppeard V, Khalaj B, et al. Effects of bushfire smoke on daily mortality and hospital admissions in Sydney, Australia. Epidemiology 2010;21:47-55.

103 Qian Z, He Q, Lin HM, et al. Part 2. Association of daily mortality with ambient air pollution, and effect modification by extremely high temperature in Wuhan, China. Res Rep Health Eff Inst 2010:91-217.

$104 \mathrm{Kan} \mathrm{H}$, Chen B, Zhao N, et al. Part 1. A time-series study of ambient air pollution and daily mortality in Shanghai, China. Res Rep Health Eff Inst 2010;154:17-78.

105 Andersen ZI, Olsen TS, Andersen KK, et al. Association between short-term exposure to ultrafine particles and hospital admissions for stroke in Copenhagen, Denmark. Eur Heart J 2010;31:2034-40.

106 Henrotin JB, Zeller M, Lorgis L, et al. Evidence of the role of short-term exposure to ozone on ischaemic cerebral and cardiac events: the Dijon Vascular Project (DIVA). Heart 2010;96:1990-6

107 Thach T-Q, Wong C-M, Chan K-P, et al. Air pollutants and health outcomes: assessment of confounding by influenza. Atmosph Environ 2010;44:1437-42.

108 Stafoggia M, Forastiere F, Faustini A, et al. Susceptibility factors to ozone-related mortality: a population-based case-crossover analysis. Am / Respir Crit Care Med 2010:182:376-84

109 Revich B, Shaposhnikov D. The effects of particulate and ozone pollution on mortality in Moscow, Russia. Air Qual Atmos Health 2010;3:117-23.

110 Mate T, Guaita R, Pichiule M, et al. Short-term effect of fine particulate matter (PM 2.5) on daily mortality due to diseases of the circulatory system in Madrid (Spain). Sci Total Environ 2010:408:5750-7.

111 Vichit-Vadakan N, Vajanapoom N, Ostro B. Part 3. Estimating the effects of air pollution on mortality in Bangkok, Thailand. Res Rep Health Eff Inst 2010;154:231-68.

112 Ren C, Melly S, Schwartz J. Modifiers of short-term effects of ozone on mortality in eastern Massachusetts-a case-crossover analysis at individual level. Environ Health 2010;9:3.

113 O’Donnell MJ, Fang J, Mittleman MA, et al. Fine particulate air pollution (PM2.5) and the risk of acute ischemic stroke. Epidemiology 2011;22:422-31.

114 Li G, Zhou M, Cai Y, et al. Does temperature enhance acute mortality effects of ambient particle pollution in Tianjin City, China. Sci Total Environ 2011;409:1811-7.

115 Sicard P. Lesne 0 , Alexandre $N$, et al. Air quality trends and potential health effects-development of an aggregate risk index. Atmosph Environ 2011;45:1145-53.

116 Chiusolo M, Cadum E, Stafoggia M, et al. Short term effects of nitrogen dioxide on mortality and susceptibility factors in 10 Italian cities: the EpiAir study. Environ Health Perspect 2011;119:1233-8.

117 Mallone S, Stafoggia M, Faustini A, et al. Saharan dust and associations between particulate matter and daily mortality in Rome, Italy. Environ Health Perspect 2011;119:1409-14.

118 Yorifuji T, Kawachi I, Sakamoto T, et al. Associations of outdoor air pollution with hemorrhagic stroke mortality. J Occup Environ Med 2011:53:124-6.

119 Jimenez E, Linares C, Martinez D, et al. Particulate air pollution and short-term mortality due to specific causes among the elderly in Madrid (Spain): seasonal differences. Int I Environ Health Res 2011;21:372-90.

120 Lall R, Ito K, Thurston GD. Distributed lag analyses of daily hospital admissions and source-apportioned fine particle air pollution. Environ Health Perspect 2011:119:455-60.

121 Amancio CT, Nascimento LF. Association of sulfur dioxide exposure with circulatory system deaths in a medium-sized city in Brazil. Braz Med Biol Res 2012;45:1080-5.

122 Nascimento LF, Francisco JB, Patto MB, et al. Environmental pollutants and stroke-related hospital admissions. Cad Saude Publica 2012;28:1319-24.

123 Romieu I, Gouveia N, Cifuentes LA, et al. Multicity study of air pollution and mortality in Latin America (the ESCALA study). Res Rep Health Eff Inst 2012;171:5-86.

124 Villeneuve PJ, Johnson JY, Pasichnyk D, et al. Short-term effects of ambient air pollution on stroke: who is most vulnerable? Sci Total Environ 2012;430:193-201.

125 Szyszkowicz M, Porada E, Tremblay N, et al. Sulfur dioxide and emergency department visits for stroke and seizure. Stroke Res Treat 2012;2012:824724.

126 Valdes A, Zanobetti A, Halonen Jl, et al. Elemental concentrations of ambient particles and cause specific mortality in Santiago, Chile: a time series study. Environ Health 2012;11:82.

127 Chen R, Zhang Y, Yang C, et al. Acute effect of ambient air pollution on stroke mortality in the China air pollution and health effects study. Stroke 2013;44:954-60.

128 Mechtouff L, Canoui-Poitrine F, Schott AM, et al. Lack of association between air pollutant exposure and short-term risk of ischaemic stroke in Lyon, France. Int J Stroke 2012;7:669-74. 
129 Corea F, Silvestrelli G, Baccarelli A, et al. Airborne pollutants and lacunar stroke: a case cross-over analysis on stroke unit admissions. Neurol Int 2012:4:e11.

130 Hori A, Hashizume M, Tsuda Y, et al. Effects of weather variability and air pollutants on emergency admissions for cardiovascular and cerebrovascular diseases. Int J Environ Health Res 2012;22:416-30.

131 Turin TC, Kita Y, Rumana N, et al. Short-term exposure to air pollution and incidence of stroke and acute myocardial infarction in a Japanese population. Neuroepidemiology 2012;38:84-92.

132 Wichmann J, Voyi K. Ambient air pollution exposure and respiratory, cardiovascular and cerebrovascular mortality in Cape Town, South Africa: 2001-2006. Int J Environ Res Public Health 2012;9:3978-4016.

133 Diaz J, Tobias A, Linares C. Saharan dust and association between particulate matter and case-specific mortality: a case-crossover analysis in Madrid (Spain). Environ Health 2012;11:11.

134 Perez L, Tobias A, Querol X, et al. Saharan dust, particulate matter and cause-specific mortality: a case-crossover study in Barcelona (Spain). Environ Int 2012;48:150-5.

135 Bedada GB, Smith CJ, Tyrrell PJ, et al. Short-term effects of ambient particulates and gaseous pollutants on the incidence of transient ischaemic attack and minor stroke: a case-crossover study. Environ Health 2012;11:77.

136 Kloog I, Coull BA, Zanobetti A, et al. Acute and chronic effects of particles on hospital admissions in New-England. PLoS One 2012;7:e34664.

137 Kim SY, Peel JL, Hannigan MP, et al. The temporal lag structure of short-term associations of fine particulate matter chemical constituents and cardiovascular and respiratory hospitalizations. Environ Health Perspect 2012;120:1094-9.

138 Leiva GM, Santibanez DA, Ibarra ES, et al. A five-year study of particulate matter (PM2.5) and cerebrovascular diseases. Environ Pollut 2013;181:1-6.

139 Qian Y, Zhu M, Cai B, et al. Epidemiological evidence on association between ambient air pollution and stroke mortality. J Epidemiol Community Health 2013;67:635-40.

140 Xiang H, Mertz KJ, Arena VC, et al. Estimation of short-term effects of air pollution on stroke hospital admissions in Wuhan, China. PLoS One 2013;8:e61168.

141 Zheng S, Wang M, Wang S, et al. Short-term effects of gaseous pollutants and particulate matter on daily hospital admissions for cardiocerebrovascular disease in Lanzhou: evidence from a heavily polluted city in China. Int J Environ Res Public Health 2013;10:462-77.

142 Carlsen HK, Forsberg B, Meister K, et al. Ozone is associated with cardiopulmonary and stroke emergency hospital visits in Reykjavik, Iceland 2003-2009. Environ Health 2013;12:28.
143 Alessandrini ER, Stafoggia M, Faustini A, et al. Saharan dust and the association between particulate matter and daily hospitalisations in Rome, Italy. Occup Environ Med 2013;70:432-4.

144 Gianicolo EA, Bruni A, Mangia C, et al. Acute effects of urban and industrial pollution in a government-designated "Environmental risk area": the case of Brindisi, Italy. Int I Environ Health Res 2013;23:446-60.

145 Scarinzi C, Alessandrini ER, Chiusolo M, et al. [Air pollution and urgent hospital admissions in 25 Italian cities: results from the EpiAir2 project]. Epidemiol Prev 2013:37:230-41.

146 Alessandrini ER, Faustini A, Chiusolo M, et al. [Air pollution and mortality in twenty-five Italian cities: results of the EpiAir2 Project]. Epidemiol Prev 2013:37:220-9.

147 Yorifuji T, Kashima S. Associations of particulate matter with stroke mortality: a multicity study in Japan. J Occup Environ Med 2013;55:768-71.

148 Chiu HF, Yang CY. Short-term effects of fine particulate air pollution on ischemic stroke occurrence: a case-crossover study. J Toxicol Environ Health A 2013;76:1188-97.

149 Xu X, Sun Y, Ha S, et al. Association between ozone exposure and onset of stroke in Allegheny County, Pennsylvania, USA, 1994-2000. Neuroepidemiology 2013;41:2-6.

(c) BMJ Publishing Group Ltd 2015

Appendix 1: Detailed search strategy

Appendix 2: Flow chart of included studies

Appendix 3: Contextual details of included studies: summary of study demographics and pollutants measured

Appendix 4: Contextual details of included studies: adjustment and assessment of bias

Appendix 5: Funnel plots

Appendix 6: Individual forest plots for each pollutant Appendix 7: Overall and stratified risk estimates for incident stroke and stroke mortality Appendix 8: Sensitivity analysis summarising associations between air pollution and stroke before and after removal of studies with increased risk of bias 